\title{
Effects of Systematic Changes in Commodity Arrangement on the Satisfaction of Supermarket Customers
}

\author{
DOI: 10.12776/QIP.V25I1.1497 \\ Josef Tošenovský, Filip Tošenovský, Ivana Dočkalová \\ Received: 2020-08-31 Accepted: 2021-02-19 Published: 2021-03-31
}

\begin{abstract}
Purpose: The paper investigates if relocation of goods at supermarkets, practised to boost sales, bothers customers and improves financial results of the stores. To explore this, a questionnaire-based poll was run, using questions, such as "Do you mind if commodity is not permanently in the same place?", or "While searching, do you buy anything you did not indend to buy?". Various relations are also observed. For instance, are opinions on product relocation related in any way to age of customers? The study suggests most customers are not satisfied with changes in product location, yet the practices lead to higher sales. It turns out the business principle - only satisfied customers spend more - may not be so true. In the study, some new questions also arose and were evaluated, such as the question "Which management activities have a positive effect on customers?".
\end{abstract}

Methodology/Approach: The paper relies on statistical testing, specifically on the chi-square test of independence and a test of differences in the relative frequency of occurrence of diverse phenomena. Real, empirical data are utilized.

Findings: The analysis showed that most customers dislike looking for goods, and many of them buy items that they did not intend to purchase. Thus, a paradox occurs when entrepreneurs dissatisfy customers, yet they register higher profits.

Research Limitation/Implication: The results concern a specific scientific field - microeconomic behavioural patterns at supermarkets.

Originality/Value of paper: The research presented in this paper is focused on the Czech Republic where it has not been undertaken to date. Work of this kind is not cited in the scientific literature, however.

Category: Technical paper

Keywords: commodity location; customer satisfaction; contingency tables 


\section{INTRODUCTION}

It is a common practice of many supermarkets to alter systematically the placement of their products so that customers are forced to glance at other items while going after an originally planned purchase. This practice is expected to boost sales. The aim of the presented research, which generally concerns human factors (HF) in quality management, is to learn whether searching for goods discomforts customers and whether customers really buy items they did not originally plan to buy. A confirmation of both the dissatisfaction and higher expenses would mean that the theory about satisfied customers spending more might not be generally valid. From a practical point of view, one could also ask the question of how far negatively perceived business activities can go before customers switch to competition, or how such practices can be compensated with other activities. Therefore many other relations of this sort can also studied.

The research presented in this paper is focused on the Czech Republic where it has not been undertaken to date. Work of this kind is also not mentioned in the scientific literature. Conclusions based on the research may be of interest when compared with experience from foreign supermarkets, especially when their owners and management run subsidiaries in Central and Eastern Europe.

In the past, researchers set diverse objectives focused on various business fields, gathered data from different states and employed and compared various mathematical and statistical tools. A large portion of the papers is dedicated to HF in business management (Hendrick, 1980). These articles dealt with a wide spectrum of questions ranging from more general ones, such as those related to understanding customer behaviour (Perugini and Conner, 2000; Tauber, 1972), to special issues including confidence of customers (Gefen, 2000), knowledge of relations and security (Belanger, Hiller and Smith, 2002; Jarvenpaa, Tractinsky and Vitale, 2000; Koufaris, 2002). Some very specific subjects were covered, as well - for example, purchase of clothes on the internet (Goldsmith and Goldsmith, 2002; Liang and Huang, 1998). Much attention is also paid to ecommerce where the subject of interest are measuring satisfaction (Chang, Torkzadeh and Dhillon, 2004), understanding customers (Donthu and Garcia, 1999; Limayem, Khalifa and Frini, 2000), relations between e-commerce and traditional commerce (Eastin, 2002; Farag, Krizek and Dijst, 2006), specifications of e-commerce in selected countries (Sim and Koi, 2002), issues of buying goods on the internet (Verhoef and Langerak, 2001; Walczuch and Lundgren, 2004), effects of internet promotional material on sales (Vijayasarathy and Jones, 2000; Peterson, Balasubramanian and Bronnenberg, 1997) and many others.

Various statistical methods have been used in the research, and the methods were compared to other techniques (Fabrigar et al., 1999; Hansen, Jensen and Solgaard, 2004; Widaman, 1993). Since much of the work draws on questionnaires, the question of acquiring data samples and processing them is of importance too (Krizek, Li and Handy, 2005; Ory and Mokhtarian, 2007), as is 
the methodology of composing questionnaires (Ellard and Rogers, 1993; Baumgartner and Steenkamp, 2001; Babbie, 1998). Theoretical models of the explored relations have also been designed (Dijst, Farag and Schwanen, 2008). Papers fairly often compare different sales strategies and reasons why they are preferred (Chen, Gillenson and Sherrell, 2002; Childers et al., 2001; Li, Kuo and Russell, 1999; Shang, Chen and Shen, 2005). Articles serving as a compendium and presenting a complex overview of these problems (Cao and Mokhtarian, 2005) are also of practical importance.

\section{METHODOLOGY}

In a related research work (Dočkalová, 2016) carried out at the Department of Quality Management of VŠB - Technical University of Ostrava, hundreds of randomly selected supermarket customers were polled. The selection consisted of $36.7 \%$ of men and $63.3 \%$ of women. There is generally a higher probability of women being polled because they visit supermarkets more frequently, being usually the ones in charge of home economics. Regarding educational level, $28.3 \%$ of the polled customers had no secondary education, $34.4 \%$ had a secondary education and $34.4 \%$ were university graduates.

Six age categories were also created: less than 20 years of age $(3.9 \%$ of respondents), 21-30 years of age (17.8\%), 31-40 years old (27.9\%), 41-50 years old $(22.1 \%), 51-60$ years old $(16.9 \%)$ and 61 years of age or older $(11.4 \%)$. The most populous group of all were women aged 31-40 years (18.8\%). In all but one group - that of the respondents under 20 years of age, women dominate, the most striking dominance being in the group of 50-61 years of age (25\% men, $75 \%$ women).

The respondents filled out a questionnaire containing nine questions and offered answers of the type yes, no, I do not care. Subsequently, the following was evaluated using statistical methods that involve testing significance of differences in relative frequencies of responses, analysis of means for proportions (Wludyka, Karen and Copeland, 2005) and testing independence in contingency tables:

- Do the response frequencies differ significantly, or are they the same?

- Which responses occur with an above-average frequency, average frequency and below-average frequency?

Is the type of response related to education, age or sex of the respondents?

\section{POLL RESULTS}

The results of the analysis of questionnaires are presented in section 3.1 in a unified manner: a question is stated together with possible answers, the result of the test on significant differences in responses (p-value) is presented afterwards, and an evaluation of the responses is done together with a comment. Section 3.2 
presents the analysis of relations between the responses and sex, education and age. The evaluation is described in a greater detail for questions one and two which are the main objective of the research.

\subsection{Differences in Responses}

Each respondent received a questionnaire with nine questions so that a statistical evaluation of differences in opinions, or relative frequencies of occurrence of given responses, could be performed. The results are contained in this section. Table 1 contains frequencies of provided responses and the $\mathrm{p}$-value for the test of equality of relative frequencies.

Question 1: Do you mind if goods are not permanently located in the same place?

Possible answers: yes/no/I do not care

Result: The hypothesis of equal relative frequencies of occurrence of the responses was rejected $(\mathrm{p}$-value $=0.000)$. Comparing the responses to the question, it was obvious that most customers are bothered by continuous relocation of commodity $(73.7 \%$ of them said yes compared to $12.9 \%$ saying "no", while $13.3 \%$ "did not care").

Comparisons of relative frequencies can be performed in the Statgraphics software using the option Compare/Two Samples/Hypothesis Tests/Binomial Proportions for the case of two frequencies or the option Compare/Multiple Samples/Comparison of Proportions for the case of more than two relative frequencies. The tested statement is the hypothesis $\mathrm{H}_{\mathrm{o}}: \pi_{1}=\pi_{2}=\ldots=\pi_{\mathrm{k}}$, where $\pi_{\mathrm{i}}$ is the relative frequency of the $i$-th response in the corresponding population.

Further, the analysis-of-means graph was exploited to find out which of the response frequencies differ significantly from the average. Significantly different are the responses the proportion of which either exceeds the so-called upper decision line UDL or is below the lower decision line LDL (Nelson, Wludyka and Copeland, 2005). Regarding this question, the graph shows that the "yes" response has an above-average frequency, whereas the "no" and "I do not care" responses have significant below-average frequencies. This procedure is used for all nine questions, although the graph is depicted only for the first two questions. 


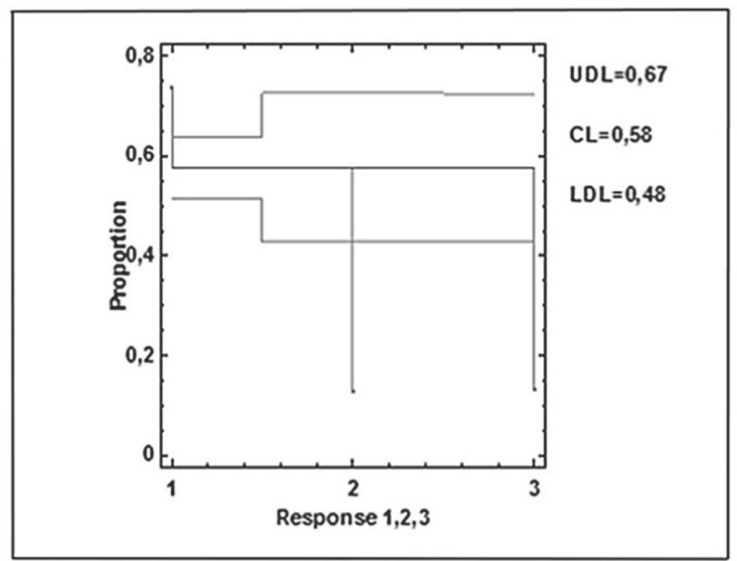

Figure 1 -Analysis-of-Means Plot for Question 1

Question 2: Do you buy anything you did not intend to buy while searching?

Possible answers: yes/no/sometimes

Result: The hypothesis of equal relative frequencies of the responses is rejected ( $p$-value $=0.0001)$. Although most customers are bothered by the need to look for relocated commodity (50.6\%), they also buy goods they originally did not want to purchase. Only $11.6 \%$ of them follow strictly their original shopping plans, whereas $37.6 \%$ shoppers buy additional items only occasionally, depending on what they spot during the shopping process. Using the graphical method, the number of "yes" responses is significantly above average, the number of "no" responses is located significantly below average and the "sometimes" response is not significantly different from the average number.

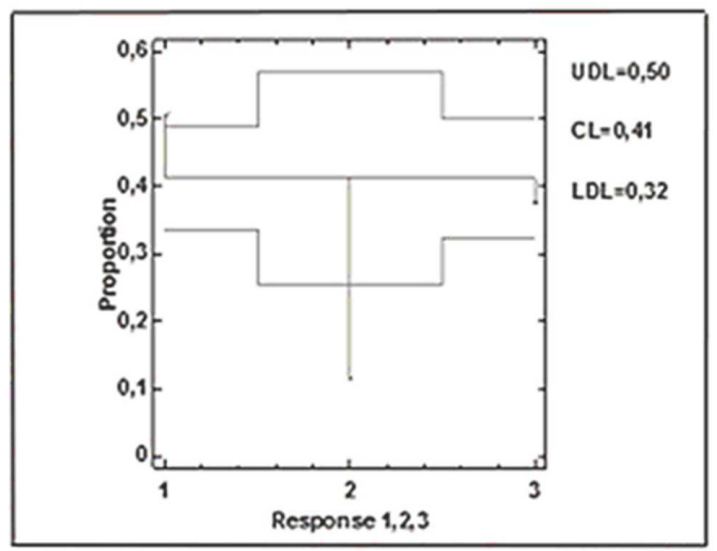

Figure 2 -Analysis-of-Means Plot for Question 2 
Question 3: Do you think supermarkets change location of goods intentionally to increase sales?

\section{Possible answers: yes/no/I do not know}

Result: The hypothesis of equal relative frequencies of the responses is rejected (p-value $=0.0001)$. Overall, $79.5 \%$ of customers believe that relocation of goods is intentional. Only $4.5 \%$ of them does not think so and $15.9 \%$ does not know.

Question 4: Do you return to such supermarkets?

Possible answers: yes/no/sometimes

Result: The hypothesis of equal relative frequencies of the responses is rejected (p-value $=0.0)$. Although a majority of customers is discontent with searching for goods, a high percentage of them (73.7\%) returns to the stores. Only 3.8\% of them goes elsewhere and $22.4 \%$ visits occasionally a different supermarket. The proportion of those who return is significantly above average, whereas the frequency of the other two responses is below average.

While exploring opinions on goods relocation, unplanned purchases and potential migration to competitive stores, other possible factors which might affect customers positively or negatively were also observed. These factors are taken into account in questions 5-9.

Question 5: Do you mind inaccessibility of shop assistants at supermarkets?

Possible answers: yes/no/sometimes

Result: The hypothesis of equal relative frequencies of the responses is rejected (p-value $=0.0013$ ). It was explored whether customers mind if there is nobody to get advice from if need be while shopping. The inaccessibility is viewed as a problem by $46.1 \%$ of customers, while $19.4 \%$ do not mind and $34.4 \%$ of shoppers only sometimes regard it as a problem. The graphical evaluation of the responses shows that the "yes" answer is well above average, the "sometimes" response has an average occurrence and the "no" response is below average, regarding the frequency of their occurrence. Therefore it is worth considering an additional number of shop assistants. Their presence is appreciated particularly when they are well-informed, kind to customers and can even remember regular visitors to their supermarket.

Question 6: Do you visit supermarkets due to discounts?

Possible answers: yes/no/sometimes

Result: The hypothesis of equal relative frequencies of the responses is rejected (p-value $=0.0090$ ). Discounts regularly benefit $43.1 \%$ of customers, they are not exploited by $20.7 \%$ of customers and they are sometimes sought after by $36 \%$ of customers. The number of clients who regularly seek discounts is not significantly above average, even though their number is the highest. The first and third responses are average in number, based on the graphical evaluation. The number of those who do not seek discounts is significantly below average. 
Question 7: Are you affected by scents at supermarkets?

Possible answers: yes/no/sometimes

Result: The hypothesis of equal relative frequencies of the responses is rejected $(\mathrm{p}$-value $=0.0)$. Pleasant scents were considered a factor that might increase interest in bakery products. The most frequent answer is no (55.5\%) and this number is significantly high, judged by the graphical method. Scents have a positive effect on $25 \%$ of customers only and sometimes on $19.4 \%$ of them. The last two numbers are significantly below average.

Question 8: Are you positively affected by music at supermarkets?

Possible answers: yes/no/sometimes

Result: The hypothesis of equal relative frequencies of the responses is rejected (p-value $=0.0)$. As in the case of scents, music does not influence most customers $(50.3 \%)$. It does have a positive effect on $30.1 \%$, which is an average number, sometimes it has a positive effect in $19.4 \%$ of cases, which is a belowaverage number.

Question 9: Are you content with commodity arrangement at supermarkets?

Possible answers: yes/no/I do not care

Result: The hypothesis of equal relative frequencies of the responses is accepted (p-value $=0.091)$. The most frequent response is the "I do not care" response (40.5\%), which however is an average number according to the analysis-ofmeans graph. An average number also concerns the responses yes and no. Thus, question 9 is answered equally in all three response categories. As is shown in Table 1, this is the only case when the responses are equally represented, regarding the population number of their occurrence. Table 1 summarizes the tests of equal occurrence of various responses.

Table 1 -Results of the Tests of Equal Occurrence of Responses

\begin{tabular}{|c|c|c|c|c|c|}
\hline Question & Answer & Frequency & Relative $f$. & $\%$ & $P$-value \\
\hline \multirow[t]{3}{*}{1} & Yes & 227 & 0.737 & 73.70 & \multirow[t]{3}{*}{0.00} \\
\hline & No & 40 & 0.1299 & 12.99 & \\
\hline & No care & 41 & 0.1331 & 13.31 & \\
\hline \multirow[t]{3}{*}{2} & Yes & 156 & 0.5065 & 50.65 & \multirow[t]{3}{*}{0.00} \\
\hline & No & 36 & 0.1169 & 11.69 & \\
\hline & At times & 116 & 0.3766 & 37.66 & \\
\hline \multirow[t]{3}{*}{3} & Yes & 245 & 0.7995 & 79.55 & \multirow[t]{3}{*}{0.00} \\
\hline & No & 14 & 0.0455 & 4.55 & \\
\hline & I do not Know & 49 & 0.159 & 15.90 & \\
\hline
\end{tabular}




\begin{tabular}{|c|c|c|c|c|c|}
\hline Question & Answer & Frequency & Relative $f$. & $\%$ & $P$-value \\
\hline \multirow[t]{3}{*}{4} & Yes & 227 & 0.737 & 73.70 & \multirow[t]{3}{*}{0.00} \\
\hline & No & 12 & 0.0389 & 3.890 & \\
\hline & At times & 69 & 0.224 & 22.4 & \\
\hline \multirow[t]{3}{*}{5} & Yes & 142 & 0.461 & 46.10 & \multirow[t]{3}{*}{0.0013} \\
\hline & No & 60 & 0.1948 & 19.48 & \\
\hline & At times & 106 & 0.3441 & 34.41 & \\
\hline \multirow[t]{3}{*}{6} & Yes & 133 & 0.4318 & 43.18 & \multirow[t]{3}{*}{0.009} \\
\hline & No & 64 & 0.2078 & 20.78 & \\
\hline & At times & 111 & 0.3604 & 36.04 & \\
\hline \multirow[t]{3}{*}{7} & Yes & 77 & 0.25 & 25 & \multirow[t]{3}{*}{0.00} \\
\hline & No & 171 & 0.5552 & 55.52 & \\
\hline & At times & 60 & 0.1948 & 19.48 & \\
\hline \multirow[t]{3}{*}{8} & Yes & 93 & 0.3019 & 30.19 & \multirow[t]{3}{*}{0.00} \\
\hline & No & 155 & 0.5032 & 50.33 & \\
\hline & At times & 60 & 0.1948 & 19.48 & \\
\hline \multirow[t]{3}{*}{9} & Yes & 104 & 0.3377 & 33.77 & \multirow[t]{3}{*}{0.091} \\
\hline & No & 79 & 0.2565 & 25.65 & \\
\hline & No care & 125 & 0.4058 & 40.58 & \\
\hline
\end{tabular}

\subsection{Relation of Responses to Sex, Education and Age}

Only differences in frequencies of occurrence of the responses have been evaluated so far. Since the answers may be different depending on sex, age and education of the respondents, an analysis has been carried out on how the three categories affect the opinions. The effects were evaluated using the chi-square test of independence. The tested hypothesis is: the two observed variables are independent.

The contingency tables are shown for the most important questions one, two and four. For the other questions, comments on the test results are presented without the tables. 
Question 1: Do you mind if goods are not permanently located in the same place?

Table 2 - Sex: Response Contingency Table

\begin{tabular}{|l|c|c|c|}
\hline & Yes & No & No care \\
\hline Male & 73 & 18 & 22 \\
\hline Female & 154 & 22 & 19 \\
\hline
\end{tabular}

Since the p-value $=0.0159$ is less than the significance level alpha of 0.05 , we reject the hypothesis that the rows and columns are independent. The observed rows are related to the columns. Women seem to be bothered more than men when they must look for goods they want to buy. At the 0.01 significance level, however, the dependence cannot be confirmed.

Table 3 - Education: Response Contingency Table

\begin{tabular}{|l|c|c|c|}
\hline & Yes & No & No care \\
\hline Elementary & 59 & 13 & 15 \\
\hline Secondary & 79 & 13 & 14 \\
\hline Tertiary & 89 & 14 & 12 \\
\hline
\end{tabular}

Since the p-value $=0.6068$ is greater than alpha $=0.05$, we cannot reject the hypothesis that the rows and columns are independent at the 0.05 significance level. The row categories may bear no relation to the column categories. Education seems to be unrelated to the relocation of commodity.

Table 4 - Age: Response Contingency Table

\begin{tabular}{|l|c|c|c|}
\hline & Yes & No & No care \\
\hline$<20$ & 4 & 4 & 4 \\
\hline $21-30$ & 38 & 11 & 6 \\
\hline $31-40$ & 60 & 12 & 14 \\
\hline $41-50$ & 57 & 5 & 6 \\
\hline $51-60$ & 41 & 5 & 5 \\
\hline$>60$ & 27 & 3 & 6 \\
\hline
\end{tabular}

The p-value equals 0.0487 . Since the p-value is roughly at 0.05 , and there is no connection between the two variables at 0.01 significance level, one cannot conclude that age is related to the opinion on goods relocation. 
Question 2: Do you buy anything you did not intend to buy while searching?

Table 5 - Sex: Response Contingency Table

\begin{tabular}{|l|c|c|c|}
\hline & Yes & No & Sometimes \\
\hline Male & 44 & 23 & 46 \\
\hline Female & 112 & 13 & 70 \\
\hline
\end{tabular}

The observed rows seem to be related to the columns, since p-value $=0.0002$. The hypothesis of no relation between the two factors is rejected. Women make an unplanned purchase more often than men $57.4 \%$ of women vs. $38.9 \%$ of men) despite the fact that they dislike commodity relocation more than men.

Table 6 - Education: Response Contingency Table

\begin{tabular}{|l|c|c|c|}
\hline & Yes & No & I do not care \\
\hline Elementary & 46 & 15 & 26 \\
\hline Secondary & 53 & 14 & 39 \\
\hline Tertiary & 57 & 7 & 51 \\
\hline
\end{tabular}

The observed rows may bear no relation to the columns. Unplanned purchases have no relation to education: $\mathrm{p}$-value $=0.075$.

Table 7 - Age: Response Contingency Table

\begin{tabular}{|l|c|c|c|}
\hline & Yes & No & No care \\
\hline$<20$ & 8 & 2 & 2 \\
\hline $21-30$ & 29 & 5 & 21 \\
\hline $31-40$ & 51 & 7 & 28 \\
\hline $41-50$ & 31 & 12 & 25 \\
\hline $51-60$ & 25 & 7 & 20 \\
\hline$>60$ & 12 & 3 & 20 \\
\hline
\end{tabular}

The observed rows may bear no relation to the columns. The inclination to buy unplanned items is not related to age: $\mathrm{p}$-value $=0.1853$.

Question 3: Do you think that supermarkets relocate goods purposefully?

Evaluations: a) the relation sex - response: the p-value $=0.5354$, which means that we cannot reject the hypothesis that the rows and columns are independent. A relation between sex and the opinion that supermarkets relocate commodity purposefully has not been proved; b) the relation education - response: the pvalue $=0.0154$. Since the $\mathrm{p}$-value is less than 0.05 , we can reject the hypothesis 
that rows and columns are independent; c) the relation age - response: the pvalue $=0.0003$. Since the $\mathrm{p}$-value is less than 0.01 , we can reject the hypothesis that rows and columns are independent. There seems to be a relation between age and the opinion on purposeful commodity relocation.

Question 4: Do you return to such supermarkets?

Table 8-Sex: Response Contingency Table

\begin{tabular}{|l|c|c|c|}
\hline & Yes & No & Sometimes \\
\hline Male & 86 & 6 & 21 \\
\hline Female & 141 & 6 & 48 \\
\hline
\end{tabular}

Since the p-value $=0.33$ is greater than 0.05 , we cannot reject the hypothesis that the rows and columns are independent at $5 \%$ significance level. The inclination to return to supermarkets where goods are relocated from time to time does not have a significant relation to the sex status.

Table 9 - Education: Response Contingency Table

\begin{tabular}{|l|c|c|c|}
\hline & Yes & No & No care \\
\hline Elementary & 63 & 5 & 19 \\
\hline Secondary & 83 & 5 & 18 \\
\hline Tertiary & 81 & 2 & 32 \\
\hline
\end{tabular}

The observed rows may have no relation to the columns, as the p-value $=0.2206$. The opinion on changing the supermarkets is not related to education.

Table 10 - Age: Response Contingency Table

\begin{tabular}{|l|c|c|c|}
\hline & Yes & No & No care \\
\hline$<20$ & 9 & 0 & 3 \\
\hline $21-30$ & 43 & 1 & 11 \\
\hline $31-40$ & 64 & 4 & 18 \\
\hline $41-50$ & 45 & 6 & 17 \\
\hline $51-60$ & 36 & 1 & 15 \\
\hline$>60$ & 30 & 0 & 5 \\
\hline
\end{tabular}

The observed rows seem unrelated to the columns: the p-value $=0.3354$. The opinion on changing the supermarket is not related to age.

For the other questions, the conclusions are stated without contingency tables. 


\section{Question 5: Do you mind if sales force is unavailable at supermarkets?}

Evaluations: a) the relation sex - response: the p-value $=0.0014$, which means, even at $1 \%$ significance level, that we can reject the hypothesis of independence of the rows and columns. Age seems to be related to the type of response to unavailability of sales personnel. In the category of men, $44.3 \%$ of respondents mind the absence of sales force, whereas $30 \%$ do not mind and $25.7 \%$ is bothered by this situation only sometimes. In the category of women, $47.7 \%$ do mind, $13.8 \%$ do not mind and $38.5 \%$ mind only sometimes; b) the relation education response: the $\mathrm{p}$-value $=0.2405$. This leads to the conclusion that we cannot reject the hypothesis of the rows and columns being independent. Education does not affect the opinion on absence of sales force; c) the relation age - response: the pvalue $=0.0519$. At the $10 \%$ significance level, this would mean that there is a relation between age and the opinion on absence of sales force, at the 5\% level, however, the test is rather inconclusive.

\section{Question 6: Do you visit supermarkets due to discounts?}

Evaluations: a) the sex - response relation: since the p-value $=0.2081$ is greater than 0.05, we cannot reject the hypothesis that the two categories are independent. Men and women take the same approach to discounts at supermarkets; b) the education - response relation: the $p$-value $=0.0468$. Visiting supermarkets due to discounts is related to education. Discounts are sought after mostly by people with secondary education $(52.9 \%)$, the least by people with tertiary education $(33 \%)$; ) the age - response relation: the $p$-value $=0.4863$, and so the opinions on discounts seem unrelated to age.

Question 7: Are you affected by scents at supermarkets?

Evaluations: a) the sex - response relation: the p-value $=0.0013$. The tested hypothesis of independence of the two categories is rejected. Women are affected by scents more than men; b) the education - response relation: the $\mathrm{p}$-value $=$ 0.4003 . The effect of scents is not related to education; c) the age - response relation: the p-value $=0.0927$. Age does not seem to be related to the perception of scents at supermarkets at the 5\% significance level.

Question 8: Are you positively affected by music at supermarkets?

Evaluations: a) the sex - response relation: the p-value $=0.3288$. Music at supermarkets does not affect men and women differently; b) the education response relation: the $p$-value $=0.4465$. The effect of music on customers is not related to education; c) the age - response relation: the $\mathrm{p}$-value $=0.2194$. Music at supermarkets is not related to age. 


\section{Question 9: Are you content with commodity arrangement at supermarkets?}

Evaluations: a) the sex - response relation: the p-value $=0.176$. The way goods are arranged at supermarkets has the same effect on women and men; b) the education - response relation: the $\mathrm{p}$-value $=0.2606$. Opinions on commodity arrangement are not related to education; c) the age - response relation: opinions on commodity arrangement are not related to age, since the $\mathrm{p}$-value $=0.3458$.

\section{CONCLUSION}

This study had two objectives: to find out how supermarket customers perceive relocation of goods, which is practised to boost sales, and to observe whether such practices do increase sale. It turns out that most customers dislike looking for goods (74\%), and many of them (50\%) buy items that they did not originally intend to purchase. Thus, from a theoretical point of view, a paradoxical situation occurs when entrepreneurs intentionally pursue activities that dissatisfy customers, yet they register higher profits. All this despite the usual assumption, given by general business management principles, that only satisfied customers return and spend more. This principle is still valid, but not in absolute terms. If a customer isn't satisfied with key business features, he or she will switch to another supermarket, if there is such a possibility. From our experience, key features include mainly commodity prices and quality. The time of purchase and difficulties given by the search for shopping items do not rank among the key features that give rise to changing the supermarket. According to our study, customers $(73 \%)$ will not change their supermarket because goods is relocated from time to time. Most of the polled customers $(85 \%)$ have encountered the practice of commodity relocation. While analysing customers' opinions on the aforementioned issues, other facts were also observed such as relations of these opinions to education, sex and age of the customer, or whether music and scents, i.e. positive business activities, generally speaking, have an effect on customers.

\section{ACKNOWLEDGEMENTS}

This paper was prepared under specific research project No. SP2020/61 and SP2020/51 of the Faculty of Materials Science and Technology, VŠB-TU Ostrava, with a support from the Ministry of Education of the Czech Republic.

\section{REFERENCES}

Babbie, E., 1998. The Practice of Social Research. Wadsworth Publishing.

Baumgartner, H. and Steenkamp, J., 2001. Response Styles in Marketing Research: A Cross-national Investigation. Journal of Marketing Research, [e-journal] 38, pp.143-156. DOI: 10.1509/jmkr.38.2.143.18840. 
Belanger, F., Hiller, J. and Smith, W., 2002. Trustworthiness in Electronic Commerce: The Role of Privacy, Security, and Site Attributes. Journal of Strategic Information Systems, [e-journal] 11(3-4), pp.245-270. DOI: 10.1016/S0963-8687(02)00018-5.

Cao, X. and Mokhtarian, P., 2005. The Intended and Actual Adoption of Online Purchasing: A Brief Review of Recent Literature. Research report UCD-ITS-RR05-07, Institute of Transportation Studies, University of California.

Chang, J.CH-J., Torkzadeh, G. and Dhillon, G., 2004. Reexamining the Measurement Models of Success for Internet Commerce. Information and Management, 41(5), pp.577-584.

Chen, L., Gillenson, M. and Sherrell, D., 2002. Enticing Online Consumers: An Extended Technology Acceptance Perspective. Information and Management, [e-journal] 39(8), pp.705-719. DOI: 10.1016/S0378-7206(01)00127-6.

Childers, T., Carr, C., Peck, J. and Carson, S., 2001. Hedonic and Utilitarian Motivations for Online Retail Shopping Behavior. Journal of Retailing, [e-journal] 77(4), pp.511-535. DOI: 10.1016/S0022-4359(01)00056-2.

Dijst, M., Farag, S. and Schwanen, T., 2008. A Comparative Study of Attitude Theory and Other Theoretical Models for Understanding Travel Behaviour. Environment and Planning, [e-journal] 40(4), pp.831-847. DOI: 10.1068/a39151.

Dočkalová, I., 2016. The Impact of Systematic Change of Goods Arrangement on Customer Satistfaction. Bachelor thesis. VSB-Technical University of Ostrava, Czech Republic.

Donthu, N. and Garcia, A., 1999. The Internet Shopper. Journal of Advertising Research, 39(2), pp.52-58.

Eastin, M., S., 2002. Diffusion of E-commerce: Analysis of the Adoption of Four E-commerce Activities. Telematics and Informatics, [e-journal] 19(3), pp.251-267. DOI: 10.1016/S0736-5853(01)00005-3.

Ellard, J. and Rogers, T., 1993. Teaching Questionnaire Construction Effectively: The Ten Commandments of Question Writing. Contemporary Social Psychology, 17(1), pp.17-20.

Fabrigar, L., Wegener, D., MacCallum, R. and Strahan, E., 1999. Evaluating the Use of Exploratory Factor Analysis in Psychological Research. Psychological Methods, [e-journal] 4(3), pp.272-299. DOI: 10.1037/1082-989X.4.3.272.

Farag, S., Krizek, K. and Dijst, M., 2006. E-shopping and its Relationship with In-store Shopping: Empirical Evidence from the Netherlands and the USA. Transport Reviews, [e-journal] 26(1), pp.43-61. DOI: 10.1080/01441640500158496.

Gefen, D., 2000. E-commerce: The Role of Familiarity and Trust. Omega, [e-journal] 28(6), pp.725-737. DOI: 10.1016/S0305-0483(00)00021-9. 
Goldsmith, R. and Goldsmith, E., 2002. Buying Apparel over the Internet. The Journal of Product and Brand Management, [e-journal] 11(2), DOI: 10.1108/10610420210423464.

Hansen, T., Jensen, J. and Solgaard, H., 2004. Predicting Online Grocery Buying Intention: A Comparison of the Tudory of Reasoned Action and the Tudory of Planned Behavior. International Journal of Information Management, [e-journal] 24(6), pp.539-550. DOI: 10.1016/j.ijinfomgt.2004.08.004.

Hendrick, H., 1980. Human Factors in Management. In: Futures in Human Factors: 1980-2000. Symposium conducted at the Human Factors Society 24th Annual Meeting. Los Angeles, USA, 1980.

Jarvenpaa, S.L., Tractinsky, N. and Vitale, M., 2000. Consumer Trust in an Internet Store. Information Technology and Management, [e-journal] 1. DOI: 10.1023/A:1019104520776, pp.45-71.

Koufaris, M., 2002. Applying the Technology Acceptance Model and Flow Theory to Online Consumer Behavior. Information Systems Research, [e-journal] 13(2), pp.205-223. DOI: 10.1287/isre.13.2.205.83.

Krizek, K., Li, Y. and Handy, S., 2005. Spatial Attributes and Patterns of Use in Household-related Information and Communications Technology Activity. Transportation Research Record: Journal of the Transportation Research Board, [e-journal] 1926(1), pp.252-259. DOI: 10.1177/0361198105192600129.

Li, H., Kuo, C. and Russell, M., 1999. The Impact of Perceived Channel Utilities, Shopping Orientations and Demographics on the Consumer's Online Buying Behavior. Journal of Computer-Mediated Communication, [e-journal] 5(2). [online] Available at: <https://onlinelibrary.wiley.com/doi/full/10.1111/j.10836101.1999.tb00336.x> [Accessed: 01 December 1999]. DOI: 10.1111/j.10836101.1999.tb00336.x.

Liang, T. and Juany, J., 1998. An Empirical Study on Consumer Acceptance of Products in Electronic Markets: A Transaction Cost Model. Decision Support Systems, 24(1998), pp.29-43.

Limayem, M., Khalifa. M. and Frini, A., 2000. What Makes Consumers Buy from Internet? A Longitudinal Study of Online Shopping. IEEE Transactions on Systems, Man and Cybernetics. Part A, 30(4), pp.421-432.

Nelson, P. R., Wludyka, P. S. and Copeland, K. A. F., 2005. The Analysis of Means: A Graphical Methods for Comparing Means, Rates and Proportions. SIAM.

Ory, D. and Mokhtarian, P., 2007. Description of a Northern California Shopping Survey Data Collection Effort. Research report UCD-ITS-RR-07-03, University of California, Davis, Institute of Transportation Studies. 
Perugini, M. and Conner, M., 2000. Predicting and Understanding Behavioral Volitions: The Interplay Between Goals and Behaviors. European Journal of Social Psychology, 30(5), pp.705-731.

Peterson, R., Balasubramanian, S. and Bronnenberg, B., 1997. Exploring the Implications of the Internet for Consumer Marketing. Journal of the Academy of Marketing Science, [e-journal] 25(4), pp.329-346. DOI: 10.1177/0092070397254005.

Shang, R., Chen, Y. and Shen, L., 2005. Extrinsic versus Intrinsic Motivations for Consumers to Shop On-line. Information and Management, [e-journal] 42, pp.401-413. DOI: 10.1016/j.im.2004.01.009.

Sim, L. and Koi, S., 2002. Singapore's Internet Shoppers and the Impact on Traditional Shopping Patterns. Journal of Retailing and Consumer Services, [e-journal] 9(2), pp.115-124. DOI: 10.1016/S0969-6989(01)00029-7.

Tauber, E., 1972. Why Do People Shop?. Journal of Marketing, 36(4), pp.46-49.

Verhoef, P. and Langerak, F., 2001. Possible Determinants of Consumers' Adoption of Electronic Grocery Shopping in the Netherlands. Journal of Retailing and Consumer Services, [e-journal] 8(5), pp.275-285. DOI: 10.1016/S0969-6989(00)00033-3.

Vijayasarathy, L. and Jones, J., 2000. Print and Internet Catalog Shopping: Assessing Attitudes and Intentions. Internet Research: Electronic Networking Applications and Policy, 10(3), pp.191-202.

Walczuch, R. and Lundgren, H., 2004. Psychological Antecedents of Institutionbased Consumer Trust in E-retailing. Information and Management, [e-journal] 42(1), pp.159-177. DOI: 10.1016/j.im.2003.12.009.

Widaman, K., 1993. Common Factor Analysis versus Principal Component Analysis: Differential Bias in Representing Model Parameters? Multivariate Behavioral Research, [e-journal] 28(3), pp.263-311. DOI: 10.1207/s15327906mbr2803_1.

Wludyka, N., Karen, A. and Copeland, K., 2005. The Analysis of Means: A Graphical Method for Comparing Means, Rates, and Proportions. Philadelphia: SIAM. 


\section{ABOUT AUTHORS \\ Josef Tošenovsk'́y $0000-0003-4684-1369$ (J.T.) - Prof., Department of Quality Management, Faculty of Materials Science and Technology, VSB-Technical University of Ostrava, Ostrava, Czech Republic, e-mail: josef.tosenovsky@vsb.cz.}

Filip Tošenovskýy $\hat{y}^{000-0003-3946-7815}$ (F.T.) - Assist. Prof., Department of Quality Management, Faculty of Materials Science and Technology, VSB-Technical University of Ostrava, Ostrava, Czech Republic, e-mail: filip.tosenovsky@vsb.cz.

Ivana Dočkalová (I.D.) - Alumnus of VSB-Technical University of Ostrava, Ostrava, Czech Republic.

\section{AUTHOR CONTRIBUTIONS}

Conceptualization, J.T.; Methodology, J.T.; Software, I.D.; Validation, J.T. and F.T.; Formal analysis, J.T., F.T. and I.D.; Investigation, I.D.; Resources, I.D.; Data curation, I.D.; Original draft preparation, J.T. and F.T.; Review and editing, J.T. and F.T.; Visualization, J.T and F.T.; Supervision, F.T.; Project administration, J.T., F.T. and I.D.; Funding acquisition, J.T. and F.T.

\section{CONFLICTS OF INTEREST}

The authors declare no conflict of interest. The funders had no role in the design of the study; in the collection, analyses, or interpretation of data; in the writing of the manuscript, or in the decision to publish the results.

(C) 2021 by the authors. Submitted for possible open access publication under the terms and conditions of the Creative Commons Attribution (CC-BY) license (http://creativecommons.org/licenses/by/4.0/). 